\title{
Le Mecklembourg-Poméranie-Occidentale, un littoral touristique entre réhabilitation et ancrage dans une aire allemande et baltique
}

Mecklenburg-Western Pomerania, a tourist coastline caught between rehabilitation and rootedness in a German-Baltic area Mecklemburgo-Pomerania Occidental, un litoral turístico entre su rehabilitación y la permanencia en una zona alemana y báltica

\section{Lauriane Létocart}

\section{OpenEdition}

\section{Journals}

Édition électronique

URL : https://journals.openedition.org/mappemonde/5281

DOI : 10.4000/mappemonde.5281

ISSN : $1769-7298$

\section{Éditeur}

UMR ESPACE

Référence électronique

Lauriane Létocart, "Le Mecklembourg-Poméranie-Occidentale, un littoral touristique entre

réhabilitation et ancrage dans une aire allemande et baltique », Mappemonde [En ligne], 130 | 2021, mis en ligne le 15 mars 2021, consulté le 20 mai 2021. URL : http://journals.openedition.org/ mappemonde/5281 ; DOI : https://doi.org/10.4000/mappemonde.5281

Ce document a été généré automatiquement le 20 mai 2021. 


\title{
Le Mecklembourg-Poméranie- Occidentale, un littoral touristique entre réhabilitation et ancrage dans une aire allemande et baltique
}

\author{
Mecklenburg-Western Pomerania, a tourist coastline caught between \\ rehabilitation and rootedness in a German-Baltic area \\ Mecklemburgo-Pomerania Occidental, un litoral turístico entre su rehabilitación \\ y la permanencia en una zona alemana y báltica
}

Lauriane Létocart

"Swinemünde [Swinoujscie] a été merveilleusement bien rénovée! C'était une ville allemande autrefois, on y trouve la même architecture, la promenade. Mais c'est beaucoup plus vivant qu'ici, on peut y danser. Il y a des lumières la nuit, contrairement à ici où tout est trop calme. Et les prix sont beaucoup plus attractifs ! $»^{1}$ La description de cette station balnéaire polonaise, la plus proche de la frontière avec l'Allemagne, est celle du guichetier du théâtre Chapeau Rouge à Heringsdorf, station balnéaire allemande de l'île d'Usedom également proche de la frontière. Elle met en lumière la situation du littoral baltique du Mecklembourg-Poméranie-Occidentale, ancien littoral touristique au temps de la Prusse, aujourd'hui confronté à la concurrence de la Pologne. En effet, ce littoral a été l'un des berceaux du tourisme balnéaire allemand qui connaît des dynamiques à la fois classiques et propres à l'histoire d'un Land de l'ancienne République démocratique allemande (RDA). Espace le plus fréquenté du Land par les touristes (figure 1), il cherche à s'affirmer face à ses voisins, le littoral du SchleswigHolstein et celui de la Pologne (figure 2). En effet, le premier, riche de son passé touristique, dont le symbole est la station de Travemünde, décrite par Thomas Mann dans Les Buddenbrooks (vaste saga d'une riche famille marchande de Lübeck qui rejoint, à la meilleure saison, les côtes de la Baltique allemande à l'instar de la riche bourgeoisie de la ville hanséatique), a connu un développement touristique relativement important dans la seconde moitié du XXe siècle. Le second appartient à l'aire de l'ancienne Prusse, 
avec notamment la station de Swinoujscie, et connaît, depuis l'adhésion de la Pologne à l'UE, un développement touristique récent, attirant une clientèle touristique plus jeune. Dans un contexte de concurrence et d'intégration baltique, le tourisme apparaît alors comme un enjeu notable pour le Mecklembourg-Poméranie-Occidentale.

Figure 1. Le littoral, l'espace attractif du Mecklembourg-Poméranie-Occidentale

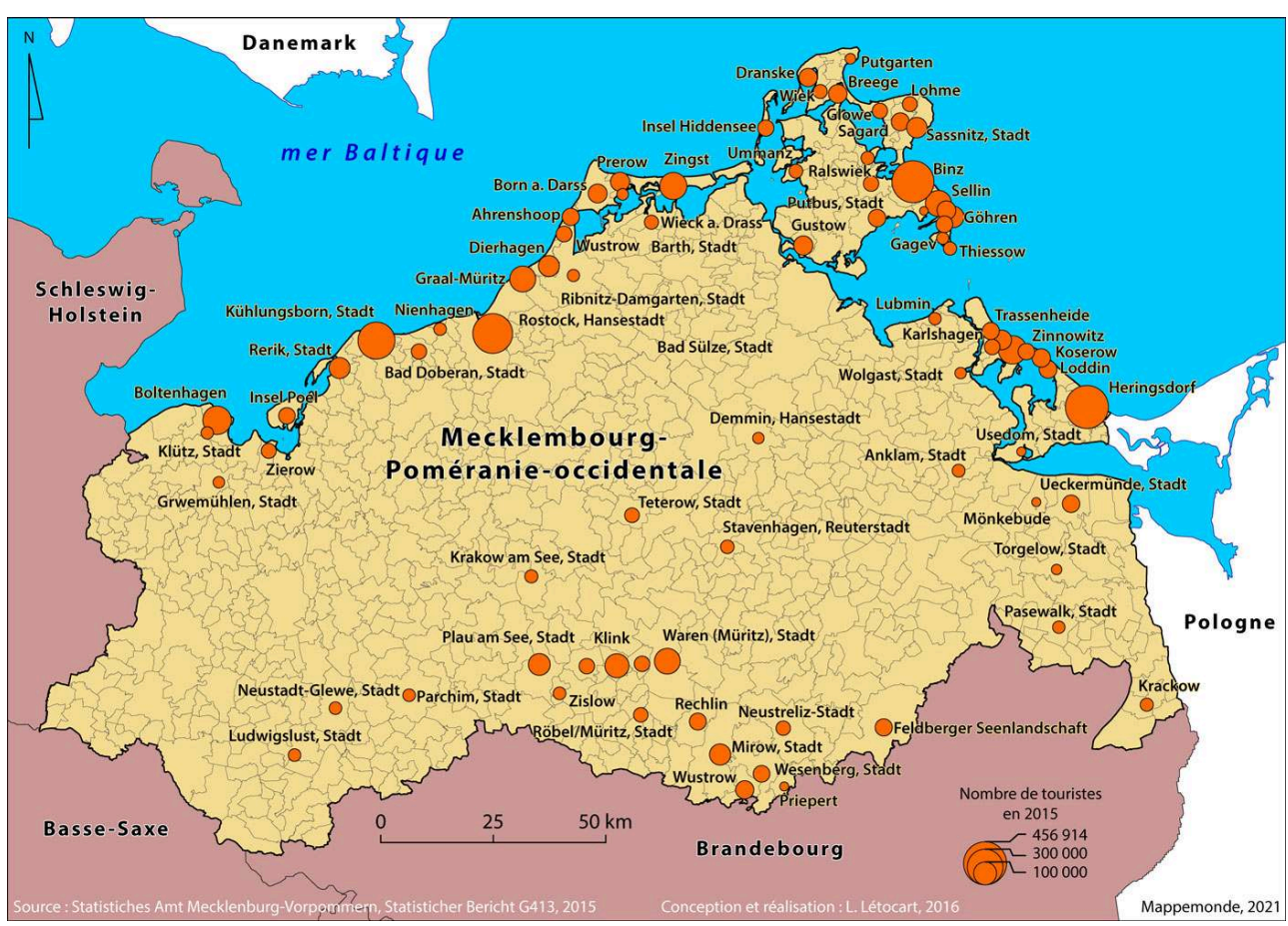

Arrivées des touristes en 2015.

Source : Statistiches Amt Mecklenburg-Vorpommern, Statisticher Bericht G413, 2015 ; Réalisation : Létocart, 2016 
Figure 2. Localisation du Land de Mecklembourg-Poméranie-Occidentale dans l'espace baltique

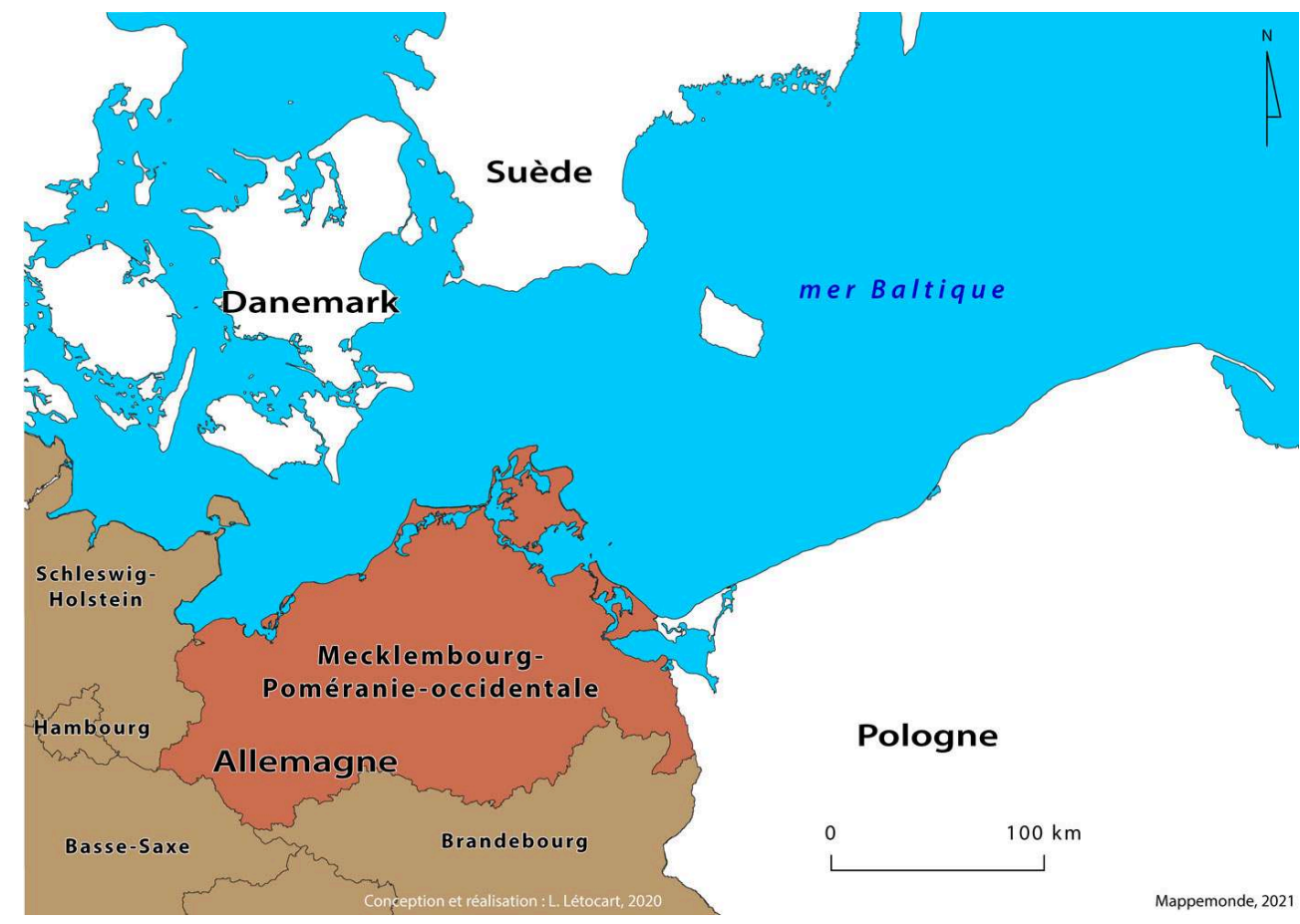

\section{Un berceau du tourisme affaibli ? Le tourisme, révélateur de l'histoire de l'Allemagne}

\section{Le littoral baltique du Mecklembourg-Poméranie-Occidentale : un haut lieu du tourisme balnéaire allemand}

En Allemagne, les côtes baltiques du Mecklembourg-Poméranie-Occidentale ont été les premières à avoir été valorisées touristiquement. En 1793, le duc Frédéric-François de Mecklembourg fonde, sous les recommandations de Samuel Gottlieb Vogel, professeur de médecine à l'université de Rostock, la station d'Heiligendamm (Karge, 2008). Cette dernière est aménagée autour de l'usage thérapeutique du bain, suivant le modèle anglais de Bath. Elle participe au développement touristique du littoral baltique, d'autres stations émergent également comme Boltenhagen, impulsée par la famille du comte Bothmer dès 1803, Warnemünde fondée en 1805, Heringsdorf en $1817 \ldots$ (figure 3). 
Figure 3. Périodes de développement des stations balnéaires du Land de MecklembourgPoméranie-Occidentale

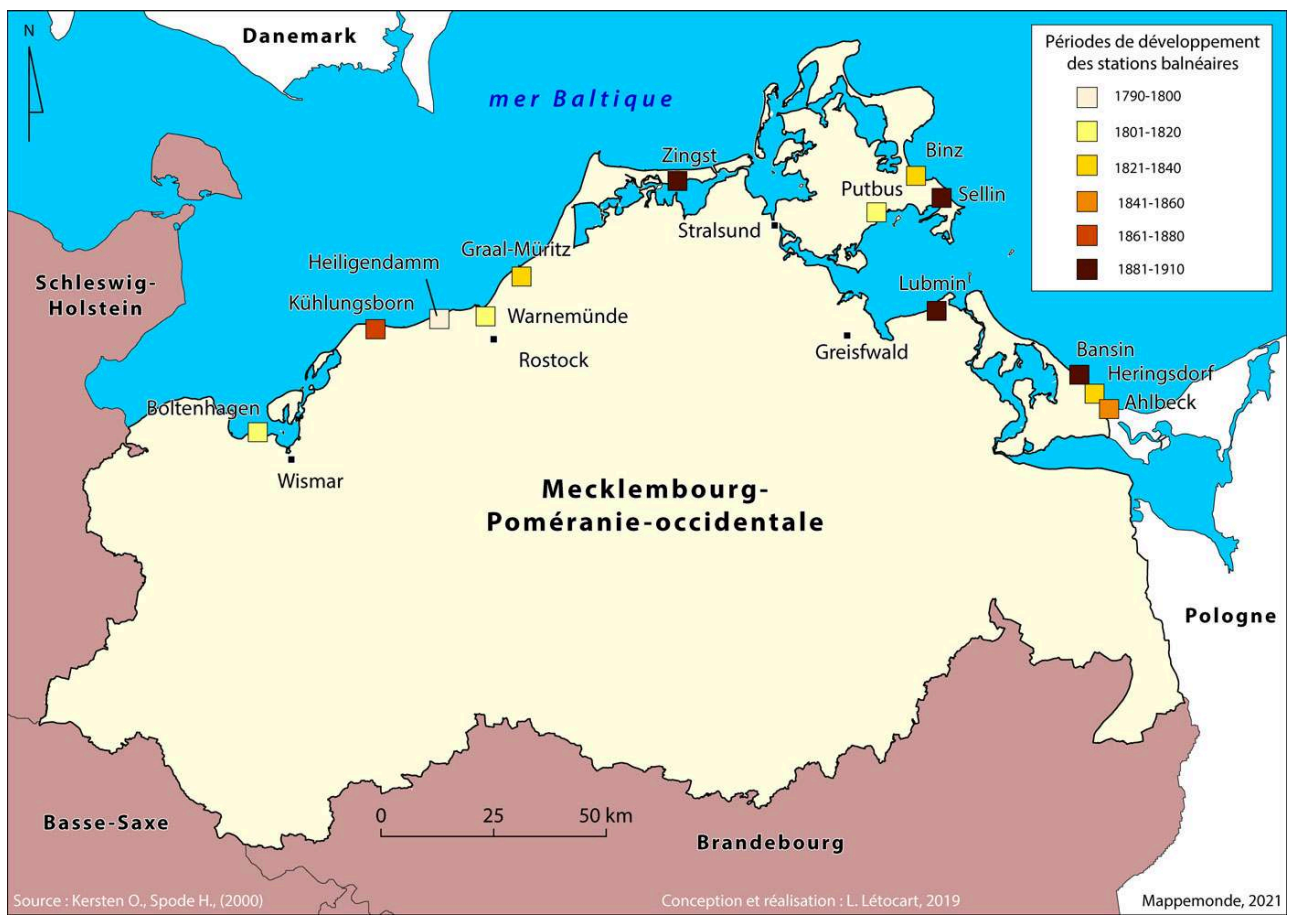

Source : Kersten O., Spode H., (2000) ; Réalisation : Létocart, 2019

3 Toutes ces stations répondent à un développement classique du tourisme de la fin du $\mathrm{XVIII}^{\mathrm{e}}$ siècle - première moitié du XIX ${ }^{\mathrm{e}}$ siècle : un lieu fondé par la noblesse à des fins d'abord thérapeutiques et essentiellement fréquenté lors de la saison estivale. À partir de cabines sur roues ou pilotis, les premiers touristes plongeaient directement dans l'eau froide de la Baltique afin de profiter de ses vertus curatives. Quant aux promenades et aux jetées, elles permettaient de profiter des bienfaits de l'air marin. Toute une société mondaine, puis bourgeoise, a ainsi participé au dynamisme de ces stations, se retrouvant autour de quelques lieux emblématiques : le casino, la place de concert, la jetée - lieu d'appontement des navires, mais aussi, et surtout, lieu de parade et de sociabilité touristique. En cela, rien peut-être de bien singulier par rapport aux autres littoraux allemands ou Nord européens, si ce n'est que ce développement touristique témoigne de l'importance de la mer Baltique pour la Prusse puis pour l'Allemagne wilhelmienne.

Cet espace du tourisme balnéaire allemand est aussi confirmé, dans les années 1930, par l'aménagement du centre de vacances de Prora, situé sur l'île de Rügen, construit entre 1936 et 1939. S'étendant sur 4,5 km, ce vaste complexe de béton, devant accueillir 20 000 vacanciers, était administré par l'organisation nazie Kraft durch Freude (La force par la joie) (Spode, 2004). Si Prora n'a jamais servi au tourisme en raison du déclenchement de la Seconde Guerre mondiale, le lieu témoigne cependant du développement volontariste d'un tourisme populaire de « masse » sur la côte baltique. Cette station, et à travers elle le littoral baltique, a servi activement la propagande nazie, son architecte, Clemens Klotz, ayant reçu en 1937 le Grand Prix de l'Architecture lors de l'Exposition universelle de Paris (Rostock, Zadnicek, 2012).

5 Ainsi, les premiers développements touristiques du littoral du Land révèlent une certaine attractivité de cette portion du littoral baltique. D’une part, la Baltique, ou 
plutôt ses eaux fraîches (sur l'île de Rügen, par exemple, la température de l'eau de mer s'élève en moyenne à $16^{\circ} \mathrm{C}$ en juillet-août) et l'air marin vigoureux sont prisés pour leurs vertus thérapeutiques, en faisant une mer appréciée et recherchée par l'aristocratie et la bourgeoisie allemande, voire nord-européenne. D'autre part, la renommée de la Baltique est aussi récupérée par le $\mathrm{III}^{\mathrm{e}}$ Reich pour y développer un tourisme populaire et servir la propagande nazie. Cette réputation de la mer baltique, et du littoral de Mecklembourg-Poméranie-Occidentale en particulier, est également due à la proximité de Berlin, située à moins de $250 \mathrm{~km}$, qui fait de ce littoral baltique «la baignoire des Berlinois $»^{2}$. Ainsi, nombre de stations sont fréquentées par l'élite politique, économique et intellectuelle de Berlin. Par exemple, Heringsdorf doit en partie sa réputation aux hommes d'état: la famille impériale allemande, le conseiller d'État Karl von Triest et aux intellectuels de l'époque tels que le dramaturge Heinrich Laube, les Frères Grimm, Theodore Fontane ou encore Henirich Mann (Gildenhaar, 2008). Ce dernier, dans les années 1930, écrivait : « [à] Trois heures et demie de train et vous trouverez un magnifique et confortable quartier d'hôtels et de villas au bord de la mer. Ça prend cinq heures en voiture. Il en résulte qu'Heringsdorf est encore plus fréquentée par les baigneurs berlinois le week-end ». Les réseaux de transport entre Berlin et la côte baltique sont alors une clé de compréhension du développement touristique, même si des travaux récents évitent "d'inféoder le tourisme au transport » (Gay, Mondou, 2017). En effet, les réseaux de transports demeurent perfectibles. Si la liaison autoroutière s'est développée après la réunification, avec notamment la construction de l'A20 en 1992 permettant de connecter la Baltique du MecklembourgPoméranie-Occidentale au réseau ouest-allemand et européen, les liaisons ferroviaires font également l'objet d'améliorations. Si toutes les grandes villes du Land et les îles de Rügen et Usedom sont reliées à Berlin, une modernisation des dessertes est prévue par le plan fédéral des transports 2030. Ce projet permettrait de réduire de moitié le temps de parcours entre Berlin et l'île d'Usedom, celui-ci passant de 4 heures à 2 heures, et de pallier l'abandon en 2014 du Usedom Express, train saisonnier direct avec Berlin mis en arrêt en raison de sa faible rentabilité. Quant à la liaison aérienne, deux aéroports sont implantés à Rostock et Heringsdorf. Leurs liaisons sont polarisées autour de l'espace germanophone. L'aéroport de Rostock est notamment en relation avec Munich et Vienne, et celui d'Heringsdorf avec Dortmund, Düsseldorf, Francfort-sur-le-Main, Stuttgart et Zürich. Avec 31000 passagers en 2018, Heringsdorf fait figure de petit aéroport saisonnier. Quant à Rostock, ses 296027 passagers en 2018 lui confèrent un statut de pôle régional modeste.

\section{Des héritages touristiques à gérer dans le contexte d'intégration d'un nouveau Land}

6 Après la réunification allemande, le littoral baltique devient un symbole du "passé fardeau » de l'Allemagne. L'empreinte nazie avec le complexe de Prora et le centre d'expérimentation technique de Peenemünde sur l'île d'Usedom en 1936 est forte. Plusieurs zones, jusqu'alors touristiques, vont être marquées par les implantations militaires, comme Tarnewitz, proche de Boltenhagen, qui devient un centre d'essai de l'aviation allemande, la presqu'île de Wüstrow, proche de la station de Rerik, aménagée en école de tir de Flak (défense anti-aérienne), ou encore Kühlungsborn qui abrite un centre de tir. L'époque de la RDA marque aussi une continuité dans l'usage militaire de la côte, l'armée nationale populaire reprenant souvent les anciennes bases nazies. À 
Kühlungsborn, un commandement des nageurs de combat s'implante. Le complexe touristique de Prora est reconverti de manière partielle en une caserne de parachutistes. L'image d'une mer-frontière, militarisée sous la RDA s'éloigne alors de celle de la mer-plaisir des vacances. Les touristes côtoient ainsi les militaires, l'armée étant aussi présente dans les centres de vacances via des manifestations sportives (Scheibe, 2005). Néanmoins, si des conflits d'usage ont pu se manifester entre vacanciers et armée, les flux touristiques ne se sont pas taris pour autant. L'État estallemand, considérant le tourisme comme un moyen de renouveler la force de travail, " décide, réalise, dirige, contrôle directement ou indirectement pratiquement tout ce qui touche aux équipements et à l'animation récréatifs. » (Dewailly, 1990). Le tourisme socialiste, via la nationalisation des infrastructures hôtelières par l'Aktion Rose ${ }^{3}$ se développe, transformant villas et hôtels du XIX siècle en centres d'hébergement populaire. Par exemple, à Kühlungsborn, le nombre de vacanciers du Freie Deutsche Gewerkschaftsbund (FDGB) bondit à partir de 1949, année de la fondation de la RDA (figure 4).

Figure 4. Nombre de vacanciers du FDGB à Kühlungsborn entre 1947 et 1955

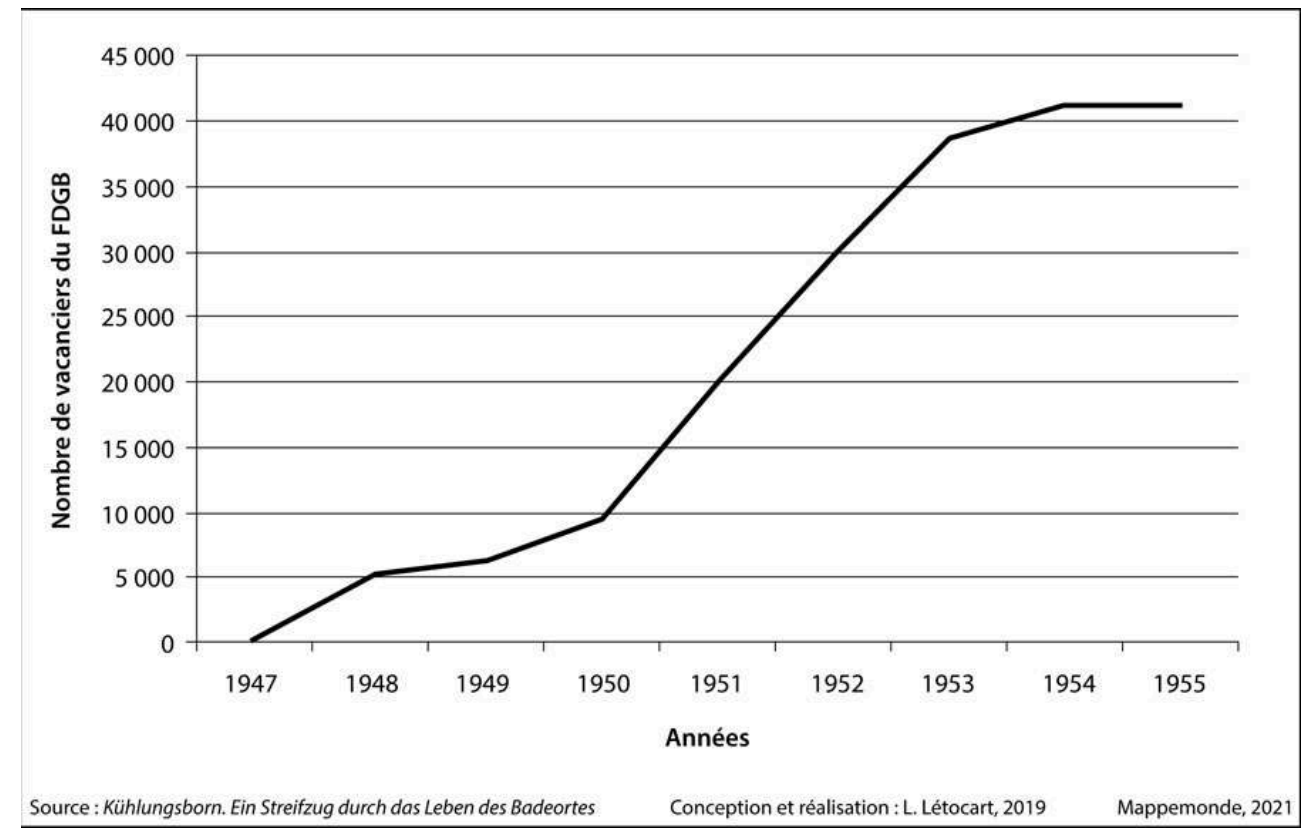

Une nette croissance avec la création de la RDA à partir de 1949.

Source : Kühlungsborn. Ein Streifzug durch das Leben des Badeortes ; réalisation : Létocart, 2019

7 L'empreinte militaire pose davantage question pour le développement touristique après la réunification, par la pollution de nombreux sites et la situation économique du Land (tableau 1).

Tableau 1. Reconversion des sites militaires en zones touristiques

\begin{tabular}{|c|c|c|c|c|}
\hline Lieu & $\begin{array}{l}\text { Usage militaire } \\
\text { initial }\end{array}$ & $\begin{array}{l}\text { Reconversion } \\
\text { envisagée }\end{array}$ & État en 2005 & État en 2018 \\
\hline
\end{tabular}




\begin{tabular}{|c|c|c|c|c|}
\hline Tarnewitz & $\begin{array}{l}\text { Centre d'essai de la } \\
\text { Luftwaffe. (III }{ }^{\mathrm{e}} \text { Reich) }\end{array}$ & Marina & $\begin{array}{l}\text { Début des } \\
\text { travaux incertain }\end{array}$ & $\begin{array}{l}\text { Ouverte depuis } 2008 . \\
\text { Nouveaux } \\
\text { investissements } \\
\text { prévus }\end{array}$ \\
\hline $\begin{array}{l}\text { Presqu'île de } \\
\text { Wustrow }\end{array}$ & $\begin{array}{l}\text { École d'artilleurs de la } \\
\text { Flak. (III }{ }^{\mathrm{e}} \text { Reich) }\end{array}$ & $\begin{array}{ll}\text { Centre de } & \text { de } \\
\text { vacances. } & \end{array}$ & $\begin{array}{l}\text { Suspension de la } \\
\text { procédure } \\
\text { d'aménagement } \\
\text { du territoire. }\end{array}$ & $\begin{array}{l}\text { Pas d'aménagement. } \\
\text { Péninsule toujours } \\
\text { fermée au public, } \\
\text { accessible uniquement } \\
\text { par bateau et calèche }\end{array}$ \\
\hline Darßer Ort & Port militaire (RDA) & $\begin{array}{l}\text { Parc national/ } \\
\text { port de refuge }\end{array}$ & $\begin{array}{l}\text { Aménagement } \\
\text { nécessaire, mais } \\
\text { difficile }\end{array}$ & $\begin{array}{l}\text { Problème } \\
\text { d'envasement. Projet } \\
\text { controversé d'un port } \\
\text { de plaisance à Prerow }\end{array}$ \\
\hline $\begin{array}{l}\text { Arkona } \\
\text { (Bunker) }\end{array}$ & $\begin{array}{l}\text { Poste de } \\
\text { commandement } \\
\text { protégé (RDA) }\end{array}$ & Usage muséal & $\begin{array}{l}\text { Réalisation } \\
\text { terminée. }\end{array}$ & \\
\hline Prora & Caserne de la NVA & $\begin{array}{l}\text { Utilisation } \\
\text { polyvalente }\end{array}$ & $\begin{array}{l}\text { Conception } \\
\text { controversée } \\
\text { après la vente à } \\
\text { des investisseurs } \\
\text { privés }\end{array}$ & $\begin{array}{l}\text { Programme } \\
\text { immobilier achevé. } \\
\text { Situation incertaine } \\
\text { pour le centre de } \\
\text { documentation. } \\
\text { Quelques blocs en } \\
\text { friche }\end{array}$ \\
\hline $\begin{array}{l}\text { Saßnitz- } \\
\text { Dwasieden }\end{array}$ & $\begin{array}{l}\text { Détachements de la } \\
\text { Marine (III }{ }^{\mathrm{e}} \text { Reich) }\end{array}$ & $\begin{array}{l}\text { Parc de station } \\
\text { thermale }\end{array}$ & $\begin{array}{l}\text { Réalisation } \\
\text { terminée }\end{array}$ & \\
\hline Bug-Dranske & Hydrobase (III ${ }^{\mathrm{e}}$ Reich) & $\begin{array}{l}\text { Centre de } \\
\text { vacances/ } \\
\text { marina }\end{array}$ & $\begin{array}{l}\text { Gel du projet, } \\
\text { absence } \\
\text { d'investisseur }\end{array}$ & \\
\hline Zingst-Ost & $\begin{array}{l}\text { Terrain de tir }\left(\mathrm{III}^{\mathrm{e}}\right. \\
\text { Reich })\end{array}$ & $\begin{array}{l}\text { Aquarium } \\
\text { géant }\end{array}$ & $\begin{array}{l}\text { Début des } \\
\text { travaux incertain }\end{array}$ & \\
\hline $\begin{array}{l}\text { Stralsund- } \\
\text { Dänholm }\end{array}$ & Base militaire (RDA) & $\begin{array}{l}\text { Utilisation } \\
\text { polyvalente }\end{array}$ & $\begin{array}{l}\text { Réalisation } \\
\text { terminée }\end{array}$ & \\
\hline Peenemünde & $\begin{array}{l}\text { Centre } \\
\text { d'expérimentation de } \\
\text { la Heer (V1 et V2) et } \\
\text { base d'essai de la } \\
\text { Luftwaffe (III Reich) }\end{array}$ & $\begin{array}{l}\text { Utilisation } \\
\text { polyvalente }\end{array}$ & $\begin{array}{l}\text { Manque } \\
\text { d'investisseur }\end{array}$ & $\begin{array}{l}\text { Musée, } \\
\text { développement } \\
\text { port }\end{array}$ \\
\hline $\begin{array}{l}\text { Wolgast- } \\
\text { Südhafen }\end{array}$ & Chantier naval (RDA) & $\begin{array}{l}\text { Usage } \\
\text { commercial }\end{array}$ & $\begin{array}{l}\text { Réalisation } \\
\text { terminée }\end{array}$ & \\
\hline
\end{tabular}




\begin{tabular}{|l|ll|l|l|l|}
\hline $\begin{array}{l}\text { Greifswald- } \\
\text { Ladebow }\end{array}$ & $\begin{array}{l}\text { Base aérienne } \\
\text { Reich })\end{array}$ & $\left(\mathrm{III} \mathrm{e}^{\mathrm{e}}\right.$ & $\begin{array}{l}\text { Usage } \\
\text { Réalisation } \\
\text { terminée/ } \\
\text { future marina } \\
\text { procédure en } \\
\text { cours }\end{array}$ & Achèvement \\
\hline
\end{tabular}

Source : Scheibe, 2015 ; réalisation : Létocart, 2019

8 Si certains sites militaires ont connu un processus de patrimonialisation, à l'instar de Peenemünde, centre d'essai des armes nazies V1 et V2, et de son musée technique ouvert en 1991, ou du mirador de la zone frontière de Kühlungsborn transformé en lieu de mémoire des transfuges d'Allemagne de l'Est, d'autres sont tombés dans l'oubli ou font l'objet de conflits d'acteurs récurrents. Ainsi, le complexe de Prora (photo 1), après le départ de l'armée populaire est-allemande, a soulevé de nombreux débats.

\section{Photo 1. Le complexe de Prora}

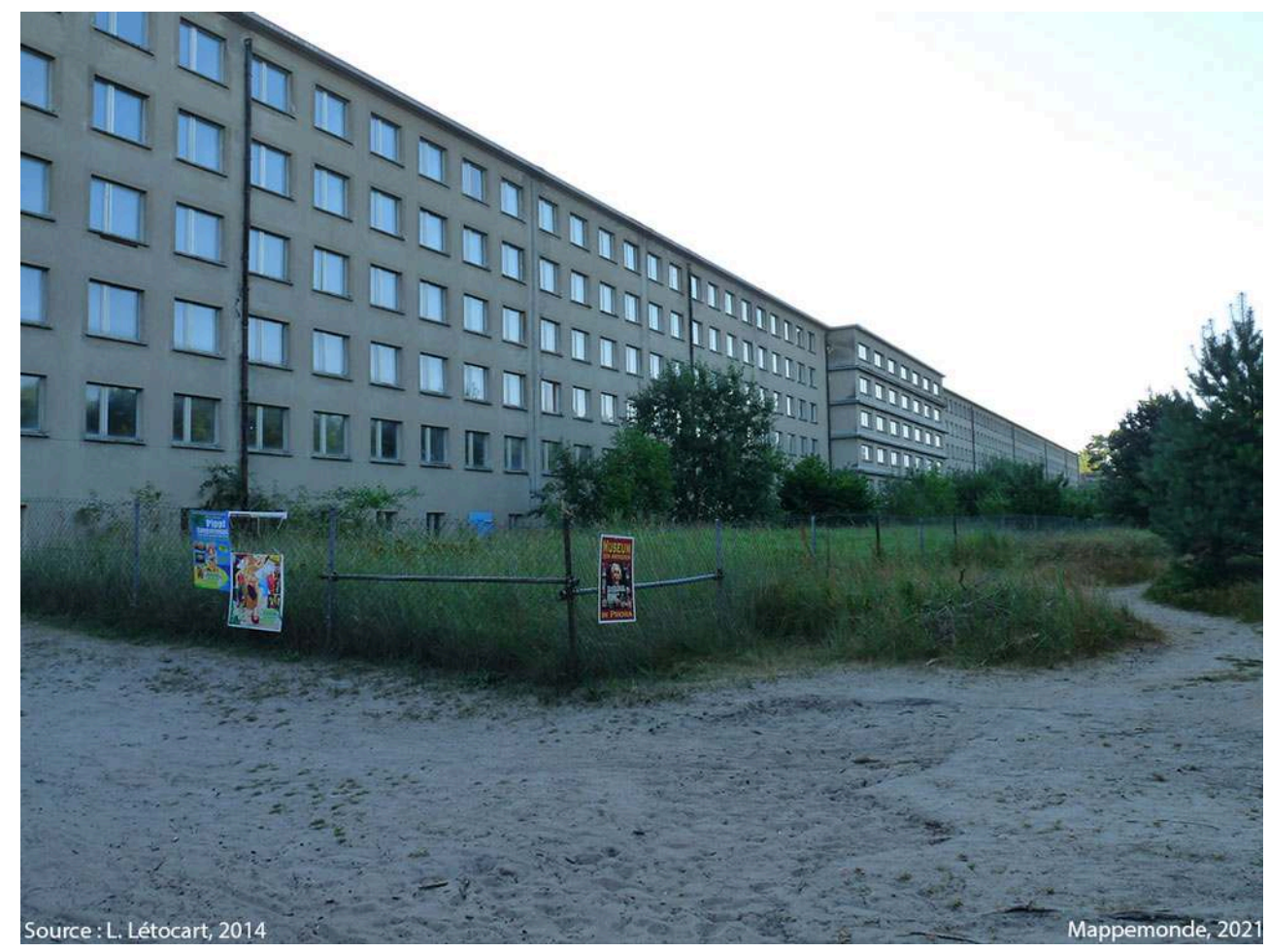

Source : Létocart, 2014

9 Le désengagement des autorités publiques y est assez significatif, l'ensemble ayant été vendu à des investisseurs privés, essentiellement allemands. La décennie 2010 marque la transformation progressive du site en lieu touristique "ordinaire ». En 2011, une auberge de jeunesse ouvre et depuis 2017-2018, la réhabilitation des autres portions du site est quasiment achevée. En effet, une partie du bloc 3 a été aménagée par la société Binz-Prora pour y construire 250 résidences, un hôtel de 210 chambres et un centre commercial et sportif. Quant au bloc 1, réhabilité par le groupe Neues Prora, il se développe autour d'une copropriété de 116 appartements, d'un centre de fitness et de santé, de commerces et de parkings de 618 places. Le panneau promotionnel des travaux situé au niveau du bloc 1 (photo 2) résume le projet de reconversion du site de Prora : « un monument mondialement connu devient une oasis de bien-être »; «ici, le 
nouveau produit phare de Prora voit le jour »; «je veux de la mer pour la vie». Une jeune femme en maillot prend un bain de soleil sur un Strankorb, fauteuil de plage que l'on retrouve sur l'ensemble des plages de la Baltique. L'image sombre de ce complexe de l'Allemagne nazie s'en trouve progressivement estompée.

Photo 2. Travaux de réhabilitation menés à Prora par le groupe Neues Prora

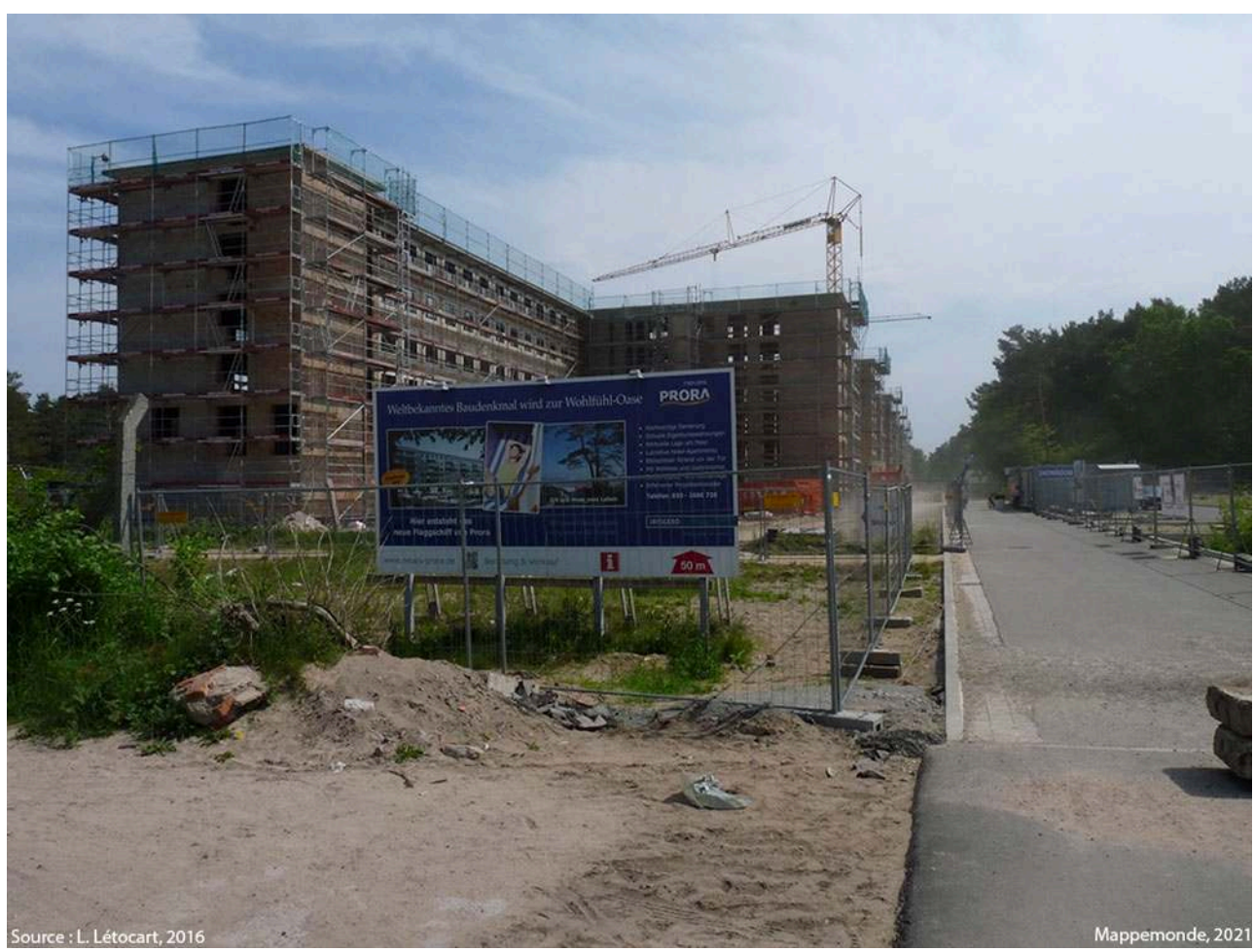

\section{Entre réhabilitation et spéculation touristique : des dynamiques touristiques de transition}

Depuis les années 1990 et 2000, les aménagements touristiques semblent suivre une même chronologie: une première phase de réhabilitation des infrastructures touristiques suivie d'une seconde de spéculation immobilière. Ces deux tendances révèlent le dilemme des acteurs du tourisme: promouvoir le littoral du Land en conservant une clientèle traditionnelle, âgée ou familiale d'une part ; élargir l'offre à une clientèle plus aisée, d'autre part. Ces stratégies permettent de répondre à la concurrence du Schleswig-Holstein, dont l'offre touristique, bien développée, s'adresse à une clientèle aisée, et de la Pologne, qui, depuis son intégration à l'UE, s'ouvre au tourisme et attire une clientèle plus jeune. 


\section{Les stations balnéaires de Mecklembourg- Poméranie-Occidentale : entre héritage populaire et restructuration}

11 La seconde moitié des années 1990 marque une longue période de réhabilitation des hôtels, villas et pensions relevant de l'architecture balnéaire des XIXe et XXe siècles. En effet, à l'époque de la RDA, la grande majorité des infrastructures d'hébergement nationalisées se sont délabrées, en raison d'un manque de volonté financière et matérielle de l'État de les entretenir et de les développer. Ainsi, les programmes de réhabilitation sont nombreux dans les stations balnéaires, comme à Heringsdorf où l'héritage de l'architecture wilhelmienne est préservé grâce à des financements subventionnés et privés, ou à Kühlungsborn, qui a connu dans les années 2000 une longue période de réhabilitation de ses villas et de ses hôtels. La priorité est alors de redonner une image de marque aux stations en valorisant le patrimoine des XIX et $\mathrm{XX}^{\mathrm{e}}$ siècles. Bien d'autres stations ont connu ces politiques d'aménagement, comme Binz ou Sellin. Dans cette dernière, un plan de rénovation s'est étendu sur une quinzaine d'années, visant à réhabiliter ou à aménager les places, les rues piétonnes ou encore le promontoire surplombant la jetée. Ce vaste programme s'est élevé à 16 millions d'euros, financé à $75 \%$ par l'UE via le FEDER, l'État et le Land et à $25 \%$ par la commune. Ces réhabilitations ont pu susciter un certain engouement de la part des touristes qui recherchaient les nouvelles offres proposées par les stations, comme les marinas ou les bars et restaurants ouverts le soir (Jahncke, 2010). Dès lors, il s'agit d'effacer progressivement les traces d'un passé touristique qui marque l'ancienne fracture de l'Allemagne et de proposer des aménagements qui répondent aux normes $\mathrm{du}$ tourisme et aux exigences des touristes, essentiellement ouest-allemands, pour qui ce littoral a été interdit pendant quarante ans et qui constituent aujourd'hui une de ses premières clientèles (figure 5). 
Figure 5. Taux des touristes séjournant dans le Mecklembourg-Poméranie-Occidental selon le Land d'origine en 2015

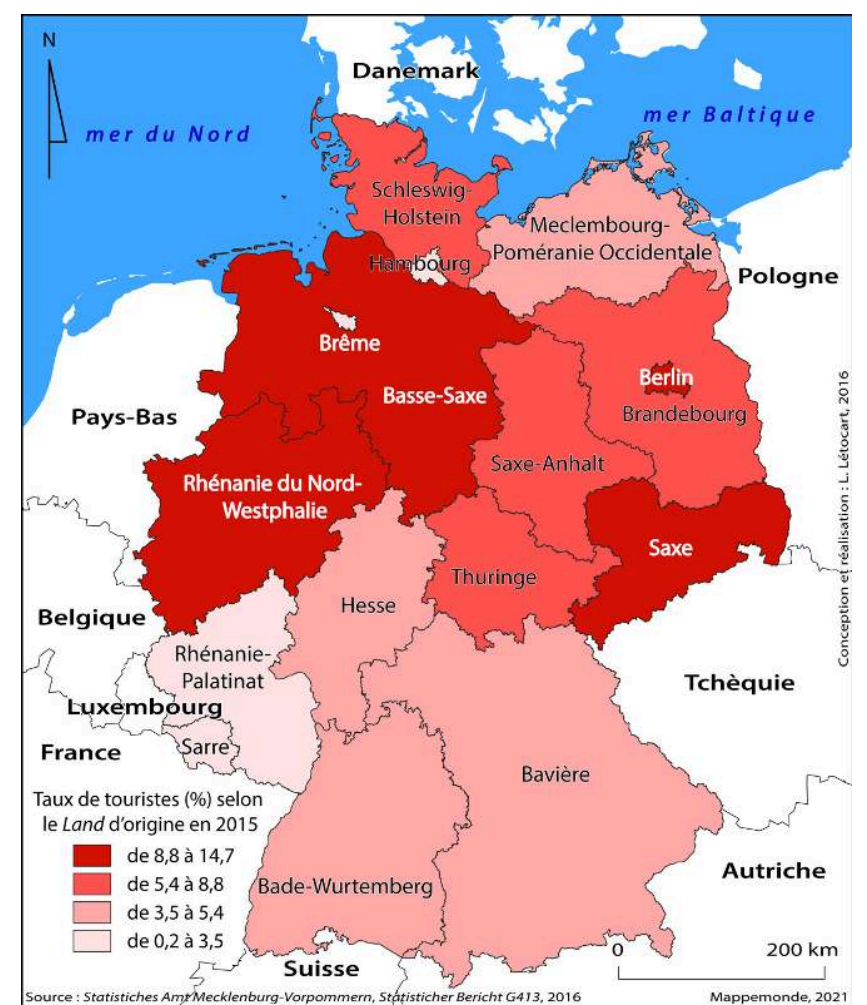

Source : Statistiches Amt Mecklenburg-Vorpommern, Statisticher Bericht G413, 2016 ; Réalisation : Létocart, 2019

Les aménagements répondent aussi à une volonté de capter une clientèle familiale. Beaucoup d'acteurs du tourisme, maires, directeurs de station, affichent le souhait d'attirer en plus grand nombre les familles. De nombreuses stations présentent à cet effet des aménagements récents de parcs et d'aires de jeux. Dans d'autres, comme à Binz ou à Ahlbeck, un festival de sculpture de sable a lieu chaque été. De plus, un label de qualité «famille » a été mis en place. Le « Familienurlaub MV - Geprüfte Qualität " ${ }^{4}$ est attribué pour une durée de trois ans aux stations qui proposent des offres adaptées aux familles, comme les activités ludiques et un certain rapport qualité-prix. En 2019, plusieurs stations de la côte ont pu bénéficier de ce label, à l'instar de Boltenhagen, Dierhagen, Göhren, les trois Kaiserbäder, Sellin, Trassenheide, Ueckermünde, Warnemünde et Zingst. Si l'hypothèse d'une volonté de ne pas rompre complètement avec l'héritage d'un tourisme populaire qui s'est développé sous la RDA peut être avancée, il n'en reste pas moins que la concurrence de la Pologne joue en faveur d'un positionnement familial des acteurs.

\section{Le littoral baltique objet de spéculations touristiques}

Un processus de modernisation des stations est aussi d'actualité, visant à renforcer l'image de prestige associée aux lieux. Ainsi, depuis les années 2000, les Kaiserbäder (île d'Usedom), Sellin et Binz (île de Rügen), ou encore Kühlungsborn ont vu se développer des infrastructures d'hébergement haut de gamme sous la houlette d'investisseurs allemands. Par exemple, à Binz, l'hôtel Cerês cinq étoiles a ouvert ses portes en 2007, jouant avec les codes d'un luxe épuré. De même, à Sellin, les travaux du Strandhotel, 
dans la Wilhelmstrasse, en plein centre de la station, en lieu et place de l'hôtel du même nom fondé en 1898, prévoient la construction de vingt-deux appartements de vacances et de vingt-trois appartements privés de très haut standing. De même, des marinas ont aussi été créées, l'aménagement le plus emblématique étant celui du port de plaisance de luxe Höhe Düne, à proximité de Warnemünde, en 2005. Il constitue un complexe touristique réservé à une clientèle aisée, dont l'accès depuis le continent est assez limité (par bac depuis Warnemünde ou par une route se terminant en cul-de-sac au niveau du port de croisière) et offrant des prestations haut de gamme (centre de spa, commerces de luxe, restaurant gastronomique).

Après la réunification, la côte baltique est aussi devenue le terrain des investisseurs d'Allemagne de l'Ouest et l'objet de vastes transactions immobilières. À Binz, par exemple, $54 \%$ des terres ont été rachetées par des Allemands de l'Ouest. Mais le projet immobilier le plus emblématique de cette spéculation a lieu à Heiligendamm (Karge, op. cit.). En 1996, la Treuhand, organisation publique chargée de privatiser les biens de l'exRDA, vend la station au groupe immobilier allemand Fundus, spécialisé dans les biens immobiliers haut de gamme, pour 18 millions de marks (soit plus de 9000000 euros). L'investisseur prévoit la rénovation du Grand Hôtel, mais également l'ouverture d'une clinique de soins esthétiques, d'un centre de thalassothérapie et d'appartements de luxe, le tout pour un montant de 232 millions d'euros. Si ce développement contemporain d'Heiligendamm s'inscrit ainsi dans la continuité des pratiques touristiques du XIXe siècle, il n'est pas sans rencontrer certains écueils. La trop grande ambition des investisseurs a eu raison de la rénovation de la station. Le Grand Hôtel, inauguré en 2003, a ainsi déposé le bilan et changé de propriétaire en 2012. D’autre part, ces aménagements s'accompagnent d'une privatisation de l'espace public. Le chemin reliant la gare à la jetée est désormais interdit au public, obligeant les touristes à faire un détour de près de $2 \mathrm{~km}$ pour rejoindre la plage. Heiligendamm devient alors une station privée, réservée à l'élite, ce qui est notamment dénoncé par Klaus-Peter Behrens et d'autres habitants dans le blog « Heiligendamm - Zoo für Reiche " (figure 6). De même, la société Fundus acquiert en 1998 la presqu'île de Wustrow afin d'y développer un complexe touristique. Le projet n'a jamais vu le jour au nom de la préservation de la nature locale et en raison de l'opposition de la commune de Rerik, refusant l'augmentation du trafic sur la seule route d'accès à la presqu'île et qui traverse la station balnéaire. 
Figure 6. Heiligendamm, une spéculation immobilière au service d'un tourisme de luxe

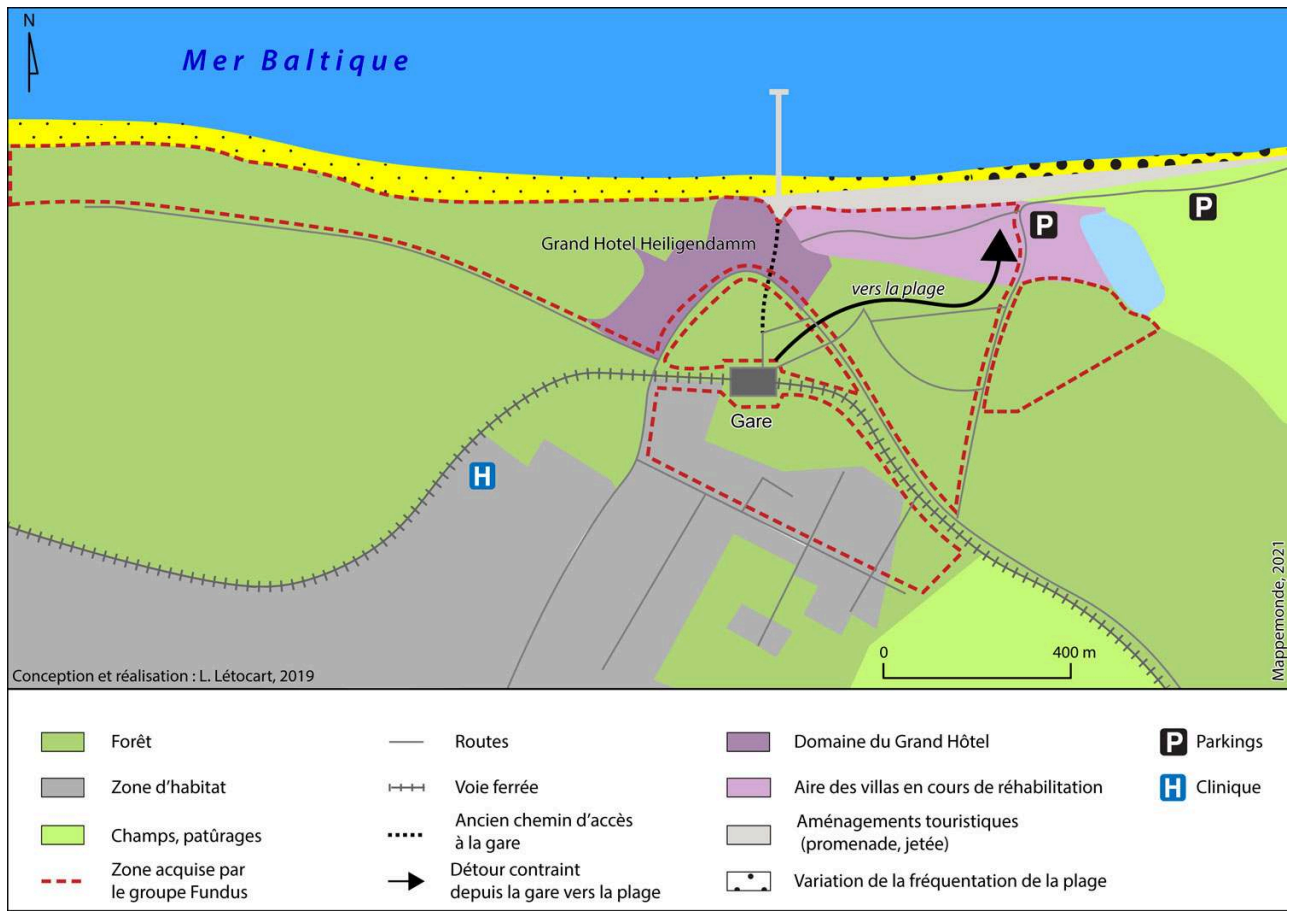

Réalisation : Létocart, 2019

\section{Des dynamiques touristiques entre affirmation de l'ancrage allemand et intégration à l'espace baltique}

L'offre touristique actuelle repose sur différentes stratégies. D'une part, elle met en valeur le patrimoine balnéaire de l'époque wilhelmienne, qui peut être considérée comme l'âge d'or du tourisme sur cette côte baltique, le romantisme allemand (XVIII ${ }^{\mathrm{e}}$ $\mathrm{XIX}^{\mathrm{e}}$ siècles) hérité des peintures de Caspar David Friedrich. D'autre part, elle montre une volonté des acteurs de s'intégrer, voire de s'affirmer, dans l'espace baltique, via le tourisme de croisière et le développement d'un tourisme de "santé " (wellness), renforçant la Baltique comme argument touristique.

\section{Affirmer un héritage allemand par le tourisme}

Depuis la réunification allemande, le patrimoine architectural et «naturel » de ce littoral baltique est mis en valeur par et pour le tourisme. Si cette stratégie est assez classique d'un engouement pour le patrimoine, elle prend une signification plus particulière dans le cadre du Mecklembourg-Poméranie-Occidentale, témoignant d'une volonté de mise en lumière d'un héritage commun à une Allemagne réunifiée. Ainsi, la période impériale est mise en relief grâce à des manifestations promouvant cet âge d'or du tourisme balnéaire. Par exemple, à Heringsdorf, les Kaisertage (journées impériales) ont lieu depuis vingt ans chaque première semaine du mois d'août et plongent les touristes dans l'époque de l'empereur Guillaume (Wilhelm) II. De même, à Binz, le «Monat der Bäderarchitecktur » (mois de l'architecture balnéaire) propose sur un mois de l'année, soit en mai, au début de la saison touristique, ou en septembre pour prolonger 
la saison, des évènements revenant sur les traces des villas et des touristes de l'époque impériale: expositions, promenades guidées et costumées, visites de villas, dîners «Belle Époque »... La période wilhelmienne est aussi mise en valeur dans les musées locaux ou régionaux, comme le Darss Museum à Prerow ou le Musée régional de Poméranie à Greifswald qui exposent des objets, images et habits de cette période (photo 3).

Photo 3. Salle du Darss-Museum présentant le développement du tourisme balnéaire à Prerow

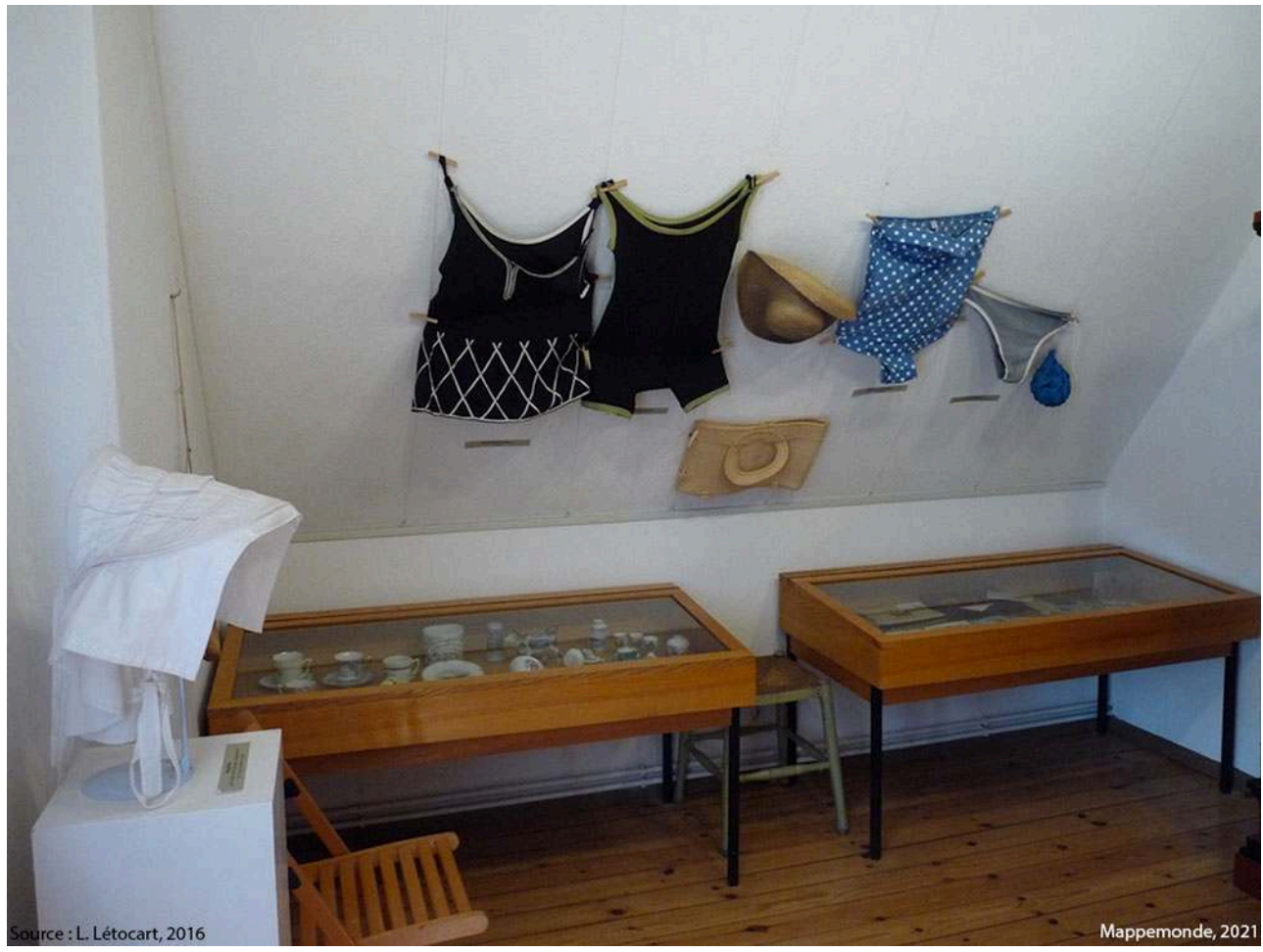

Source : Létocart, 2016

17 La période prussienne est ainsi uniquement montrée sous un jour positif, à travers la société aristocratique des loisirs et du tourisme, occultant l'image autoritaire et belliqueuse des souverains. Elle fonctionne alors comme un mythe, correspondant à l'âge d'or du tourisme littoral allemand dans ce Land de l'ex-RDA, apogée marquant à la fois la naissance du tourisme balnéaire et la grandeur de l'empire passé pour une Allemagne réunifiée, mais dont l'unité politique, économique, sociale et culturelle n'est peut-être pas encore achevée, trente ans après la disparition de la RDA. Un processus de patrimonialisation voire de mise en mémoire des lieux, mais aussi du temps est alors opéré (Lazzarotti, 2012).

18 La promotion de la culture allemande passe aussi par la mise en tourisme d'une nature héritée du romantisme allemand. Le littoral du Mecklembourg-Poméranie-Occidentale est, en effet, relativement préservé dans la mesure où la période de la RDA n'a pas correspondu à des aménagements touristiques massifs, à l'inverse de ce que le littoral du Schleswig-Holstein a pu connaître. En cela, il correspond pleinement aux attentes contemporaines des touristes. La nature maritime est alors promue comme un atout touristique, à travers notamment de nombreuses zones protégées: la réserve de biosphère au sud-ouest de Rügen (d'une superficie de $235 \mathrm{~km}^{2}$ ), deux parcs nationaux, 
le Nationalpark Vorpommersche Boddenlandschaft $\left(805 \mathrm{~km}^{2}\right)$ situés entre la presqu'île de Darss-Zingst, l'île d'Hiddensee et la côte ouest de Rügen et le parc national de Jasmund (3 003 ha) sur l'île de Rügen. La nature est une offre recherchée par une partie des touristes : en 2015, ces derniers mentionnaient dans leurs motivations le paysage et la nature à $69,8 \%$, le climat sain et le "bon air " à $61,2 \%^{6}$. Les offres touristiques soulignent l'importance de la nature sur ce littoral. Par exemple, depuis 2004, le Nationalpark-Zentrum Königssthul, situé au sein du parc national de Jasmund, sensibilise les visiteurs à la biodiversité et à la géologie des falaises de craie de l'île de Rügen. L'inscription en 2011, par l'UNESCO, d'une partie du parc national de Jasmund sur la liste du patrimoine mondial de l'humanité au titre des "forêts anciennes d'Allemagne » renforce aussi la place de la nature. Dix ans après sa création, en 2014, le centre comptait plus de trois millions de visiteurs. Cette mise en valeur touristique de la nature est en partie héritée du romantisme allemand, la perception romantique de la nature étant constitutive de la construction de la nation allemande (Depraz, 2008). Ainsi, l'ancienne présence du peintre romantique Caspar David Friedrich constitue une ressource mobilisée dans la mise en tourisme du site même du Königsstuhl d'où l'on peut voir le site originel des célèbres falaises de craie, aujourd'hui disparues, sujet de son tableau, Les Blanches Falaises de Rügen. Pour accéder au promontoire qui permet d'observer les falaises de Victoria Sicht peintes par Friedrich, le passage est étroit (photo 4). Les touristes doivent faire la queue pour photographier des falaises qui ont presque disparu sous l'action de l'érosion.

Photo 4. Promontoire offrant un point de vue sur les falaises de Victoria Sicht qui ont inspiré le tableau de Caspar David Friedrich, « Les Blanches Falaises de Rügen »

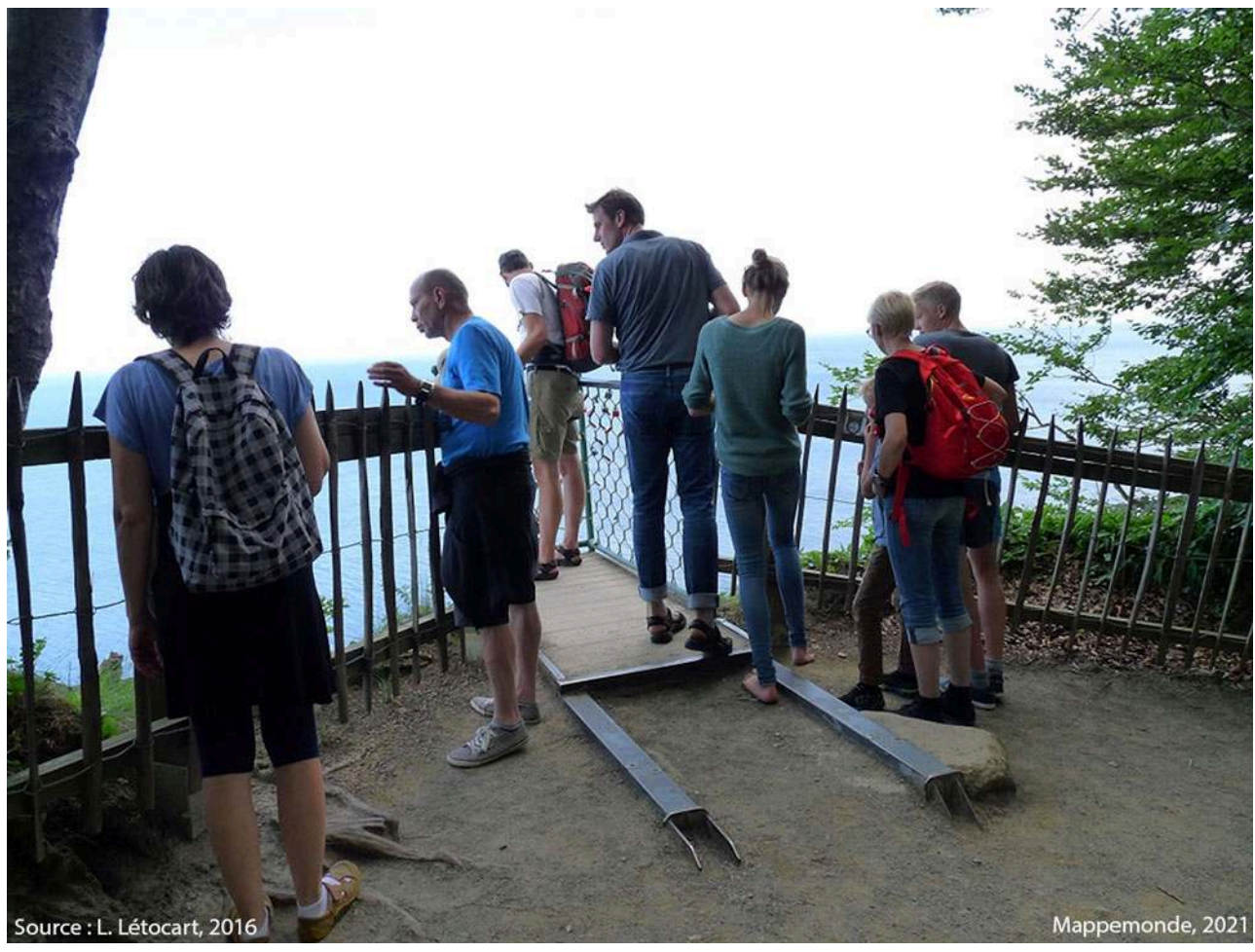

Source : Létocart, 2016 
19 Ainsi, peu importe que la photographie-souvenir ne ressemble plus au paysage peint par Friedrich. Ce qui compte, ce sont les traces du paysage romantique, qui devient en outre un objet de marketing touristique (photos 5 et 6 ).

Photo 5. Livres et produits dérivés représentant Les Blanches Falaises de Rügen du peintre romantique Caspar David Friedrich exposés dans la boutique du Nationalpark-Zentrum Königssthul

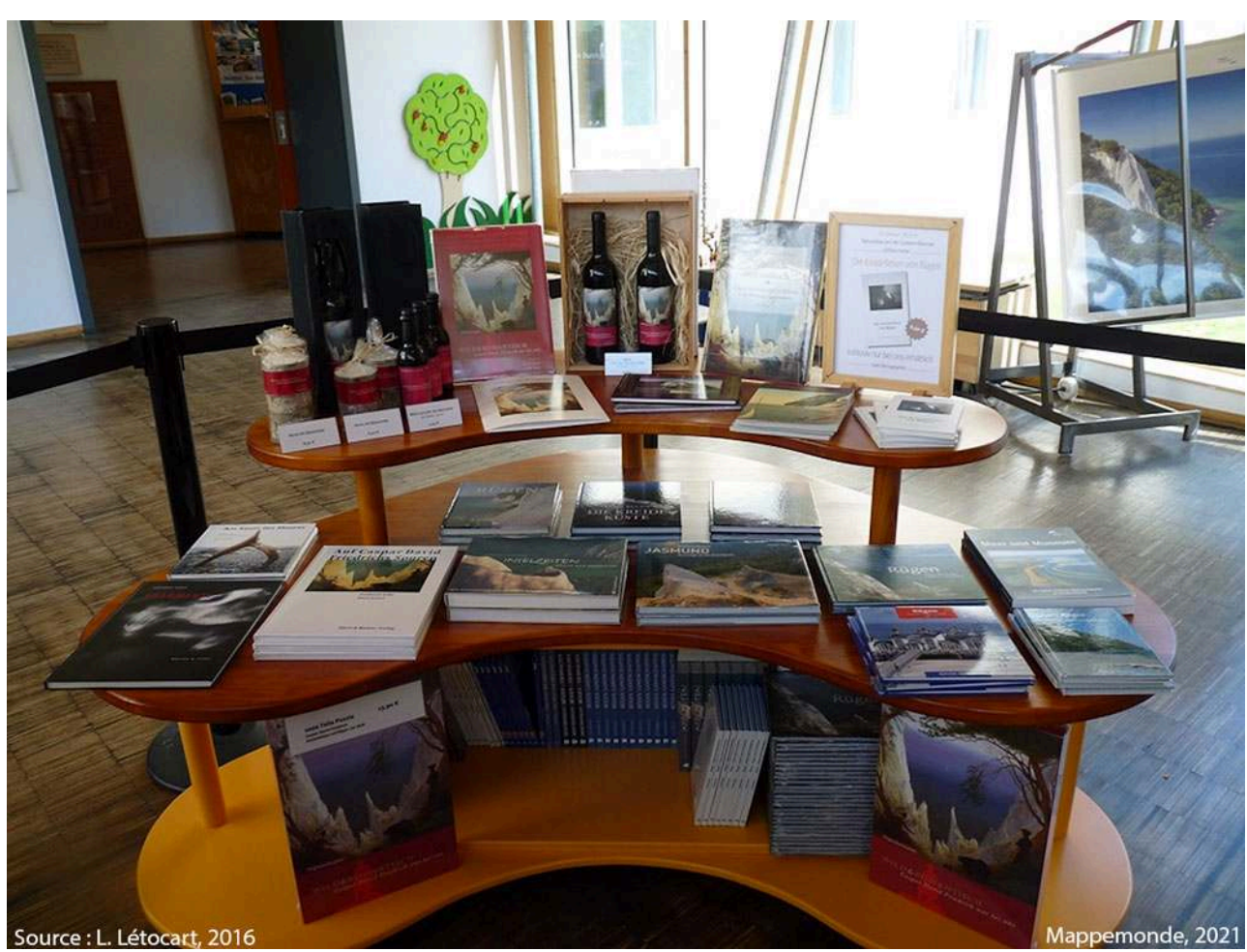

Source : Létocart, 2016 
Photo 6. L'œuvre de Caspar David Friedrich objet de marketing touristique

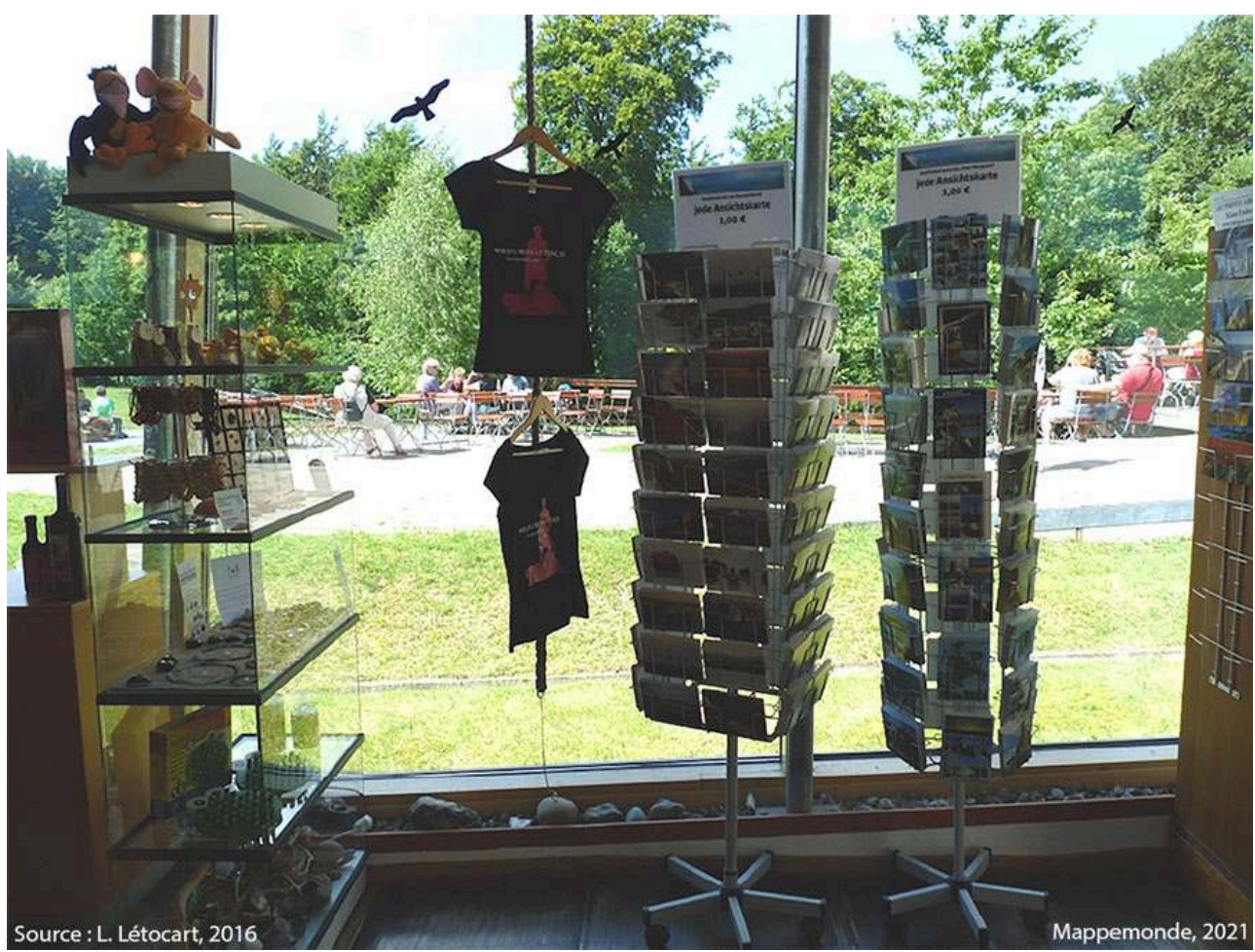

Boutique du Nationalpark-Zentrum Königssthul.

Source : Létocart, 2016

Dans la boutique à souvenirs du Nationalpark-Zentrum Königssthul, le romantisme et l'œuvre du peintre sont clairement des produits touristiques. Si les livres et les produits dérivés comme les bouteilles de vin exposent le tableau qui a rendu le site célèbre, les tee-shirts portent l'inscription "wild \& romantisch. Königsstuhl.com » et la silhouette reprend une œuvre célèbre du peintre, «Le voyageur contemplant une mer de nuages » (1818), qui représente non pas un paysage littoral, mais un paysage de montagne et qui est exposé à la Kunsthalle de Hambourg, et non dans un musée du Land.

\section{Le tourisme et l'affirmation de l'ancrage baltique du Land}

Les dynamiques touristiques prennent aussi le parti de renforcer l'ancrage de ce littoral au sein de l'espace baltique. La Baltique devient alors un outil d'intégration du Land via le tourisme. Deux stratégies nouvelles peuvent être mises en relief : le développement de la croisière et du wellness.

Depuis 2006, Rostock-Warnemünde est le port de croisière le plus important d'Allemagne. Et depuis, les acteurs de la communication du port ne cessent de s'enorgueillir de sa croissance : «Cette année, nous avons terminé la saison de croisière la plus réussie à Warnemünde jusqu'à présent » se glorifiait le directeur du port en 2008 ; " la saison de croisière bat tous les records », précisait le communiqué de presse de 2011; "record allemand de croisière pour la troisième saison consécutive » confirmait celui de 2013. Ces différents communiqués de presse témoignent l'affirmation progressive du port de Rostock-Warnemünde comme pôle de croisière sur le littoral baltique. En effet, entre 2009 et 2018, le nombre de passagers, surtout 
estivaux, a augmenté de $308 \%$, passant de 161000 à 657000 passagers. Outre le groupe allemand Aidacruise, des compagnies de croisière internationales y sont basées, comme les compagnies américaines Carnival Cruise Lines et Holland America Line, ou encore P\&O (compagnie britannique). Le port de Rostock-Warnemünde s'affirme comme port d'escale, mais aussi comme port d'embarquement et de débarquement des croisiéristes, fonction qui renforce le développement du tourisme dans le Land, puisqu'en 2015, 30 \% des passagers séjournaient dans le Land avant ou après leur croisière. Cet essor du tourisme de croisière permet aussi au Land de bénéficier d'un tourisme plus international, et notamment anglo-saxon (figure 7). De plus, le développement du tourisme de croisière inscrit le port de Rostock-Warnemünde dans l'espace baltique, dans la mesure où ce dernier fait partie du groupe Cruise Baltic, association de 18 ports majoritairement riverains de la Baltique fondée en 2005 afin de stimuler le tourisme de croisière et le tourisme des villes portuaires. Financé entre 2005 et 2007 par les fonds INTERREG de l'Union européenne, les États membres en sont aujourd'hui les principaux bailleurs de fonds.

Figure 7. Nationalités des croisiéristes à Warnemünde en 2014

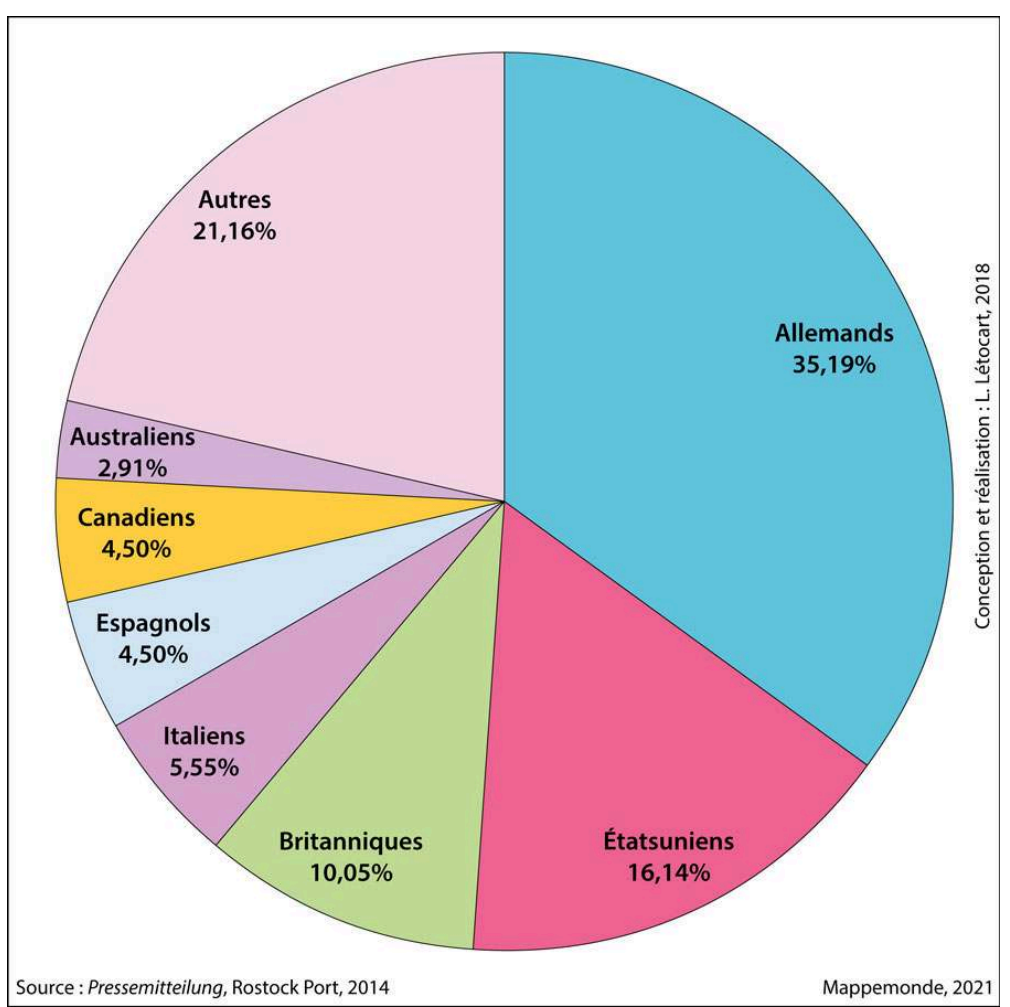

Source : Pressemitteilung, Rostock Port, 2014 ; Réalisation : Létocart, 2018

L'atout de la mer Baltique est aussi mis en avant par le renforcement du tourisme dit de santé. Ainsi, la plupart des stations balnéaires proposent des parcours de marche nordique afin de permettre aux touristes de bénéficier des bienfaits de l'air marin. Les dynamiques récentes de ce type de tourisme se manifestent surtout à Warnemünde. En concertation avec la société à responsabilité limitée, Rostocker Marketing Tourismus, la municipalité prévoit de faire de Warnemünde un pôle dédié au "tourisme de santé » à l'échelle du Land, en s'appuyant sur des infrastructures existantes comme le centre Nivea de l'hôtel Neptun et Höhe Düne. Ce projet touristique s'appuie sur un certain 
nombre d'atouts : le climat et l'air marins, ainsi qu'une tradition de thalassothérapie à Warnemünde. Ce projet, en proposant des prestations de haute qualité, s'inscrit aussi dans la montée en gamme du tourisme balnéaire.

\section{Conclusion}

Les dynamiques touristiques se déroulent dans un contexte de gestion des héritages et de concurrence croissante. Si les aménagements touristiques s'adaptent à des reconfigurations spatiales locales, nationales et européennes, il n'y a pas, pour autant, de bouleversement radical de l'offre et des structures touristiques. L'idée que les aménagements touristiques font le tourisme peut être nuancée. Ce littoral baltique du Mecklembourg-Poméranie-Occidentale en est la preuve inverse : ce sont les touristes qui font le tourisme. Ce dernier, via les goûts et les pratiques des touristes, peut être un mode de lecture d'une société, de ses évolutions, à savoir ici, une image de société allemande réunie, qui cherche à asseoir sa place au sein d'un espace baltique plus large. En outre, l'évolution du tourisme sur ce littoral reflète aussi la dimension politique du tourisme. Si ce dernier a pu être analysé comme un outil de régulation sociale, notamment sous le III ${ }^{\mathrm{e}}$ Reich et la RDA, il est aussi utilisé, dans ses représentations actuelles, comme un mythe réunificateur. Le tourisme relève alors d'une coconstruction entre les aménagements, les pratiques et les stratégies politiques.

\section{BIBLIOGRAPHIE}

DEPRAZ S. (2008). Géographie des espaces naturels protégés. Genèse, principes et enjeux territoriaux.

Paris : Armand Colin, coll. « U Géographie », 320 p. ISBN 978-2200347581

DEWAILLY J.-M. (1990). Tourisme et aménagement en Europe du Nord. Paris : Masson, coll.

« Géographie », 248 p. ISBN 978-2225818783

GAY J.-C., MONDOU V. (2017). Tourisme et transport. Deux siècles d’interactions. Paris : Bréal, 256 p.

ISBN 978-2749537436

GILDENHAAR D. (2008), Seebad Heringsdorf, die Entwicklung eines Badeortes. Ilmenau : Rhino Verlag, 63 p. ISBN 978-3-939399-11-7

JAHNCKE J. (2010). Kühlungsborn. Ein Streifzug durch das Leben des Badeortes. Rostock : Verlag Redieck \& Schade GmbH, 267 p. ISBN 3-934116-54-X

KARGE W. (2008). Heiligendamm. Erstes deutches Seebad. Swerin : Demmler Verlag, 160 p.

ISBN 978-910150171

KERSTEN O., SPODE H., (2000). “Fremdenverkehr vor dem Zweiten Weltkrieg”. In C. Becker, LeibnizInstitut für Länderkunde et H. Job (éd.), Nationalatlas Bundesrepublik Deutschland. Freizeit und Tourismus. Berlin : Spektum Akademischer Verlag Heidelberg 
LAZZAROTTI O. (2012). Des lieux pour mémoires. Monuments, patrimoines et mémoires-Monde. Paris :

Armand Colin, coll. « Le temps des idées », 216 p. ISBN 978-2200277659

SCHEIBE R. (2005), “Tourismus und Militär an der Küste von MV im 20. Jh. Aspekte der Konversion militärischer Standorte zu Tourismusdestinationen”. In W. Steingrube, éd. Greifswalder Beiträge zur Regional-, Freizeit- und Tourismusforschung, Band 16, p. 73-88. ISSN 0943-7371

SPODE H. (2004). Fordism, Mass Tourism and the Third Reich: The 'Strength through Joy' Seaside Resort as an Index Fossil". Journal of Social History, vol. 38, n 1, p. 127-155

ROSTOCK J., ZADNICEK F. (2012). Paradies Ruinen. Das KdF-Seebad der Zwanzigtausend auf Rügen. Berlin : Christoph Links Verlag GmbH, 151 p. ISBN 978-3-86153-414-3

\section{NOTES}

1. Témoignage recueilli lors d'un entretien informel avec le guichetier du théâtre Chapeau Rouge à Heringsdorf, le 2 juillet 2016.

2. L'expression «Badewanne der Berliner » est à l'origine utilisée pour la station prussienne de Swinemünde, actuelle Swinoujscie en Pologne. Elle peut être étendue à un grand nombre de stations du Land de Mecklembourg-Poméranie, dans la mesure où, en 2015, 8,6 \% des touristes du Land venaient de Berlin et 10,4 \% du Brandebourg (cf. figure 6).

3. L'Aktion Rose est une mesure de nationalisation des hôtels situés sur la côte baltique prise en 1953 par le gouvernement de la RDA.

4. «Vacances en famille Mecklembourg-Poméranie-Occidentale - Qualité certifiée ».

5. « Heiligendamm : Zoo pour riches».

6. Selon l'enquête menée par la Europäische Reiseversicherung AG et la DZT (Deutschen Zentrale für Tourismus e.V.) : Qualitätsmonitor Deutschland-Tourismus.

\section{RÉSUMÉS}

Berceau du tourisme balnéaire allemand, le littoral du Mecklembourg-Poméranie-Occidentale peut apparaître comme un espace en difficulté depuis la réunification. La gestion des héritages militaires et de la RDA, ainsi que la concurrence accrue sont des enjeux pour le développement $\mathrm{du}$ tourisme balnéaire. Les acteurs du tourisme cherchent de nouvelles stratégies afin de se positionner au sein de l'espace baltique.

The cradle of German seaside tourism, the coastline of Mecklenburg-Western Pomerania, has been a complex area since reunification. Managing military and GDR heritages while facing increased competition has challenged the state's development of seaside tourism. Tourism officials are in search of new strategies in order to better position themselves within the Baltic area.

El litoral de Mecklemburgo-Pomerania Occidental, cuna del turismo costero alemán, se mantiene desde la reunificación como una zona con dificultades. La gestión del patrimonio militar y de la RDA, así como el crecimiento de la competencia, son desafíos para el desarrollo del turismo 
litoral. Hoy, los agentes turísticos buscan nuevas estrategias para posicionarse en la zona del Báltico.

\section{INDEX}

Palabras claves : Alemania, mar Báltico, competencia, rehabilitación, turismo

Keywords : Germany, Baltic sea, competition, rehabilitation, tourism

Mots-clés : Allemagne, Baltique, concurrence, réhabilitation, tourisme

Thèmes : La Baltique. Un espace d'intégration mais aussi de concurrence et de rivalités 